\author{
Emmanuelle Cambau \\ Michael Bauer
}

\section{Multi-pathogen real-time PCR system adds benefit for my patients: yes}

Received: 1 December 2014

Accepted: 28 December 2014

Published online: 27 January 2015

(C) Springer-Verlag Berlin Heidelberg and ESICM 2015

For a contrasting viewpoint, please go to doi:

10.1007/s00134-014-3607-y.

\section{E. Cambau $(-)$}

Department of Bacteriology, Lariboisiere Hospital, AP-HP, Inserm UMR1137 IAME, Univ Paris Diderot, Sorbonne Paris Cité, Paris, France

e-mail: emmanuelle.cambau@1rb.aphp.fr

\section{Bauer}

Center for Sepsis Control and Care, Jena University Hospital, Erlanger Allee 101, 07747 Jena, Germany

\section{Need for the diagnosis of bloodstream infections}

Bloodstream infections (BSI) are a major cause of death [1] and it is accepted that initiating an effective antimicrobial therapy in severe sepsis reduces mortality in a timely manner $[2,3]$. In the era of increasing resistance, knowing pathogen and antibiotic susceptibility is critical for initiating appropriate antimicrobials $[4,5]$. Unfortunately, microbial documentation of severe infections leading to BSI is still often overlooked and recognized too late for both technical and organisational reasons.

Classical tools for diagnosing BSI are blood cultures (BC), i.e. collection of a large volume of blood $(40 \mathrm{ml}$ per episode) distributed into bottles and incubated at $35-37{ }^{\circ} \mathrm{C}$ as soon as possible [6]. The time to result is long (2-3 days) because laboratories rarely work $24 / 7$ and identification and antibiotic susceptibility testing are usually performed on subcultures [7]. Only $10 \%$ of BC processed are positive and improving performance is a challenge [6,7]. Moreover, patients often receive antimicrobials for therapeutic or prophylactic purposes, and $\mathrm{BC}$ positivity rates are lower unless specific bottles are used [4].
Molecular diagnosis of BSI appeared some years ago as a second option [5, 8]. Advantages of molecular detection are (1) shorter time to results [9] and (2) detection of non-cultivable microorganisms such as many fungi and bacteria under antibiotic pressure. However, the sensitivity of molecular tests is lower than that of cultures because the sample submitted to the test is much smaller $(1.5 \mathrm{ml}$ blood vs. $40 \mathrm{ml})$ and thus the limit of reproducible detection is about $30-100$ colony forming units (CFU)/ml, compared to $1-10 \mathrm{CFU} / \mathrm{ml}$ for $\mathrm{BC}$.

\section{Are blood cultures the gold standard for BSI?}

In a recent issue, Geoffrey Warhurst and colleagues measured the performance of the LightCycler ${ }^{\circledR}$ SeptiFast (LSF) test for patients with suspected healthcare-associated BSI [10]. They also performed a systematic review for determining STARD criteria of this test [11]. Warhurst et al. compared the LSF results to BC and concluded that the sensitivity of LSF was low (LSF positive in only 47 out of 80 BC-positive cases). Interference with human DNA and the presence of PCR inhibitors in the blood [12] might explain the false-negative LSF tests. However LSF was positive in many cases where $\mathrm{BC}$ was negative, but these cases were considered as false-positives since BC served as the gold standard. In the meta-analysis of 41 studies, summary sensitivity was somewhat higher (68\%) and specificity similar $(86 \%)$ to those in Warhurst's study [10]. These values are lower than those reported in the previous meta-analysis by Chang et al. who calculated $75 \%$ sensitivity and $92 \%$ specificity for 34 studies published until 2012, again taking BC as the reference [13].

The main question is whether blood cultures can still be considered the gold standard, especially in healthcareassociated infections (HAI) where patients often receive antibiotics. Calculation of sensitivity with regard to 
clinical status and type and severity of infection seems more appropriate. Doing that, $\mathrm{BC}$ sensitivity would be only $50 \%$ in septic shock, $35 \%$ in severe sepsis, $30 \%$ in febrile neutropenia and 10-20\% overall in patients suspected of having BSI $[7,8,14]$. Therefore, blood cultures are often falsely negative. This may be due to technical reasons (see above) and clinical microbiologists should evaluate $\mathrm{BC}$ efficiency along with mandatory quality assurance studies [6]. In addition, it is well known that BC has only $70 \%$ specificity since $20-30 \%$ BC are falsely positive because of contaminants, leading to excess treatment and secondary HAI [15].

\section{If the gold standard is clinical status, how much would the performance of the molecular test change?}

With this new gold standard, the molecular test can be true-positive but BC false-negative. This would explain why, in Warhurst's study, the LSF test was positive in 97 cases where $\mathrm{BC}$ was negative, showing the presence of DNA for 123 pathogens. Compelling studies that have performed both tests in patients suspected of having BSI usually observed a higher positivity rate for molecular tests over BC (Table 1) and these results were frequently concordant with biomarkers of infection, such as C-reactive protein and procalcitonin [9].

Clinically, the most critical question is whether or not patients not covered by guideline-adherent calculated therapy are detected early and a change of therapy is initiated. Observational studies suggest that such a scenario is observed under routine conditions [9] and would not be detected by the analysis applied by Warhurst and colleagues.

\section{Which patients will benefit from molecular testing?}

In the two meta-analyses, the main criticism was the high variability of results. This is primarily due to heterogeneity of the patient populations included and illustrated by very different BSI prevalence: from $7 \%$ (below standard rate for BC quality assurance) to $47 \%$ in Dark's review. From other studies $[9,16]$, it appeared that molecular detection and $\mathrm{BC}$ are not detecting the same microbes.
Table 1 Prevalence rates for microbial documentation in the blood detecting cultivable bacteria (positive blood cultures, BC) or nucleic acids (positive molecular test) for studies on suspicion of bloodstream infections

\begin{tabular}{lrrl}
\hline Studies & $\begin{array}{l}\text { Patients } \\
(N)\end{array}$ & $\begin{array}{l}\text { BC } \\
(\%)\end{array}$ & $\begin{array}{l}\text { Molecular } \\
\text { detection } \\
\text { in blood (\%) }\end{array}$ \\
\hline Reinhart et al. (review) [8] & 7,847 & 16.5 & 34.7 \\
Bloos et al. [9] & 245 & 14.5 & 30.2 \\
Cambau et al. [16] & 1,416 & 28.2 & 39.0 \\
Warhurst et al. [10] & 922 & 8.5 & 14.5 \\
Dark et al. (review) [11] & 10,493 & 17 & 22.4 \\
\hline
\end{tabular}

This could be a reason to perform both tests in patients suspected of having BSI. The cost of adding a molecular test to BC was addressed by Alvarez et al. [17]: for 54 patients in the control group when diagnosis was restricted to $\mathrm{BC}$, the total cost was $€ 42,198$ and for 48 patients having LSF, the cost was significantly lower $(€ 32,228)$.

LSF is a highly specialized technique composed of a critical step of DNA extraction from blood and a highly specific real-time PCR. Other multi-pathogen real-time PCR systems were described and their performances are similar but with specific technical advantages of some tests, although not all are commercially available [8, 13].

Given that all the molecular tests available so far are cumbersome and need technical expertise, it seems worthwhile to apply them preferentially to severe infections such as septic shock and severe sepsis [3].

\section{Conclusions in favour of using molecular testing}

Given the mortality and morbidity rates of severe infections, the clinical microbiology laboratory should do its best in to give the etiological diagnosis as often as possible. Multi-pathogen real-time PCR systems can circumvent the lack of sensitivity and specificity of BC. We now need more rapid and automated tests with random access in order to apply them in a $24 / 7$ continuous workflow.

Conflicts of interest E. Cambau and M. Bauer have no conflict of interest for this paper.

\section{References}

1. Goto M, Al-Hasan MN (2013) Overall burden of bloodstream infection and nosocomial bloodstream infection in North America and Europe. Clin Microbiol Infect 19:501-509
2. Kumar A, Roberts D, Wood KE et al (2006) Duration of hypotension before initiation of effective antimicrobial therapy is the critical determinant of survival in human septic shock. Crit Care Med 34:1589-1596
3. Dellinger RP, Levy MM, Rhodes A et al (2013) Surviving Sepsis Campaign: international guidelines for management of severe sepsis and septic shock, 2012. Intensive Care Med 39:165-228 
4. de Kraker ME, Jarlier V, Monen JC et al (2013) The changing epidemiology of bacteraemias in Europe: trends from the European Antimicrobial Resistance Surveillance System. Clin Microbiol Infect 19:860-868

5. Timsit JF, Citerio G, Bakker J, Bassetti M, Benoit D, Cecconi M, Curtis JR, Hernandez G, Herridge M, Jaber S, Joannidis M, Papazian L, Peters M, Singer P, Smith M, Soares M, Torres A, Vieillard-Baron A, Azoulay E (2014) Year in review in Intensive Care Medicine 2013: III. Sepsis, infections, respiratory diseases, pediatrics. Intensive Care Med 40(4):471-483

6. Baron EJ, Miller JM, Weinstein MP et al (2013) A guide to utilization of the microbiology laboratory for diagnosis of infectious diseases: 2013 recommendations by the Infectious Diseases Society of America (IDSA) and the American Society for Microbiology (ASM)(a). Clin Infect Dis 57:e22-e121

7. Pautas C, Sbidian E, Hicheri Y et al (2012) A new workflow for the microbiological diagnosis of febrile neutropenia in patients with a central venous catheter. J Antimicrob Chemother 68:943-946
8. Reinhart K, Bauer M, Riedemann NC et al (2012) New approaches to sepsis: molecular diagnostics and biomarkers. Clin Microbiol Rev 25:609-634

9. Bloos F, Sachse S, Kortgen A et al (2013) Evaluation of a polymerase chain reaction assay for pathogen detection in septic patients under routine condition: an observational study. PLoS One 7:e46003

10. Warhurst G, Maddi S, Dunn G et al (2014) Diagnostic accuracy of SeptiFast multi-pathogen real-time PCR in the setting of suspected healthcareassociated bloodstream infection Intensive Care Med 41:86-93

11. Dark P, Blackwood B, Gates S et al (2014) Accuracy of LightCycler SeptiFast for the detection and identification of pathogens in the blood of patients with suspected sepsis: a systematic review and meta-analysis. Intensive Care Med 41:21-33

12. Wiesinger-Mayr H, Jordana-Lluch E, Martro E et al (2011) Establishment of a semi-automated pathogen DNA isolation from whole blood and comparison with commercially available kits. J Microbiol Methods 85:206-213
13. Chang SS, Hsieh WH, Liu TS et al (2013) Multiplex PCR system for rapid detection of pathogens in patients with presumed sepsis - a systemic review and meta-analysis. PLoS One 8:e62323

14. Brun-Buisson C, Meshaka P, Pinton P, Vallet B (2004) EPISEPSIS: a reappraisal of the epidemiology and outcome of severe sepsis in French intensive care units. Intensive Care Med 30:580-588

15. Hall KK, Lyman JA (2006) Updated review of blood culture contamination. Clin Microbiol Rev 19:788-802

16. Cambau E, Courcol R, Veerabudun V et al (2013) Does performing DNA detection in blood improves the microbial diagnosis of severe bloodstream infections? First results of the EVAMICA study. In: Proceedings of the 23rd European congress of clinical microbiology and infectious diseases, number 0673, Berlin, Germany

17. Alvarez J, Mar J, Varela-Ledo E et al (2012) Cost analysis of real-time polymerase chain reaction microbiological diagnosis in patients with septic shock. Anaesth Intensive Care 40:958-963 